EXTENDED REPORT

\title{
Radiographic progression in patients with ankylosing spondylitis after 2 years of treatment with the tumour necrosis factor $\alpha$ antibody infliximab
}

\author{
X Baraliakos, J Listing, M Rudwaleit, J Brandt, J Sieper, J Braun
}

See end of article for authors' affiliations

Correspondence to:

Professor J Braun,

Rheumazentrum

Ruhrgebiet,

Landgrafenstr 15, 44652

Herne, Germany; i.

braun@rheumazentrum-

ruhrgebiet.de

Accepted 14 March 2005

Published Online First

18 March 2005

Background: Anti-tumour necrosis factor (TNF) treatment is clinically efficacious in patients with active ankylosing spondylitis (AS) and leads to improvement of spinal inflammation, as assessed by magnetic resonance imaging. It is unclear whether anti-TNF treatment affects chronic spinal changes in AS.

Objectives: To analyse the effect of infliximab on the radiographic course of AS over 2 years.

Methods: Complete sets of lateral radiographs of the cervical spine and lumbar spine were available from 82 patients from two sources: 41 patients (group 1) had been treated with infliximab $(5 \mathrm{mg} / \mathrm{kg} / 6$ weeks) as part of a recent randomised controlled trial and 41 patients (group 2) were part of the early German AS cohort (GESPIC), without controlled interventions. Radiographs were obtained at baseline and after 2 years and scored by the modified Stokes AS Spinal Score (mSASSS).

Results: Patients in the infliximab group were older, had a longer disease duration, and more radiographic damage at baseline. The mean (SD) mSASSS change was 0.4 (2.7) and $0.7(2.8)$ for groups 1 and 2, respectively $(p=N S)$. Radiographic damage at baseline was a predictor for more radiographic progression. Patients with baseline damage who were treated with infliximab showed a trend for less radiographic progression. No correlations between clinical parameters and radiographic progression were found.

Conclusions: Patients with AS treated with infliximab had less radiographic progression after 2 years. Patients with prevalent radiographic damage are prone to develop more damage over time. Infliximab may decelerate radiographic progression in such patients. Larger studies are needed to prove that antiTNF treatment inhibits structural damage.

$\Lambda$ nkylosing spondylitis (AS) is a common chronic inflammatory rheumatic disease that affects young male and female patients ${ }^{1}$ in the second and third decade of life. The main clinical symptom is inflammatory back pain. The disease starts in the sacroiliac joints and spreads to the spine in most patients. ${ }^{2}$ Characteristic inflammatory features of AS such as sacroiliitis, spondylitis, spondylodiscitis, and spondylarthritis can be detected by conventional $x$ ray examination and, usually even better by magnetic resonance imaging (MRI) techniques. ${ }^{23}$ Most characteristic and pathognomonic for AS is the growth of syndesmophytes and other features of new bone formation, possibly leading to ankylosis and spinal fusion. Typical osteoproliferative changes, which can be detected by imaging techniques, such as radiography and MRI can be found in different spinal structures such as vertebrae, discs, zygapophyseal and costovertebral joints, entheses, and ligaments. Conventional radiography, the "gold standard" in imaging of AS for the past decades, has been included in the internationally accepted Assessment in AS (ASAS) core set for AS. ${ }^{4}$

Conventional treatment of AS with non-steroidal antiinflammatory agents and physiotherapy is the standard of care, while disease controlling antirheumatic treatment such as sulfasalazine and methotrexate is only used in subgroups of patients with AS with peripheral arthritis and remitting anterior uveitis. Treatment of patients with active AS with the anti-tumour necrosis factor (TNF) agents infliximab and etanercept has shown a much stronger clinical efficacy in randomised controlled trials (RCTs). ${ }^{56}$

Both acute and chronic changes that can be attributed to treatment can be assessed by imaging techniques. Improvement of active spinal lesions after treatment with infliximab has been demonstrated by MRI even within a short time period, ${ }^{7}$ but chronic spinal changes are mainly assessed by conventional $x$ ray examinations. ${ }^{8}$ Scoring of $\mathrm{T}_{1}$ weighted MR images has also been successfully used, ${ }^{9}$ but only by one group to date. The modified Stokes AS Spinal Score $\left(\mathrm{mSASSS}^{10}\right)$ has been identified as the most sensitive scoring method ${ }^{11}$ for evaluation of chronic spinal changes as assessed by conventional spinal $x$ ray examination in AS.

Because the ability of anti-TNF treatment to reduce or stop chronic structural changes in the spine of patients with AS has not been evaluated to date, we analysed the data of the first investigator driven multicentre study performed in Germany, which had a major influence on the approval of this drug. ${ }^{5}{ }^{12}{ }^{13}$ Because no long term, placebo controlled data are available to answer the question about structural changes we evaluated the chronic spinal changes in patients with AS who had been treated with infliximab for 2 years and compared these data with the available 2 year follow up $x$ ray scores of patients who had participated in the early cohort of German patients with AS (GESPIC), who have been treated conventionally.

\section{PATIENTS AND METHODS}

\section{Patient groups and study protocol}

All 82 patients included in this study fulfilled the modified New York diagnostic criteria for $\mathrm{AS}^{14}$ and comprised two

Abbreviations: AS, ankylosing spondylitis; BASDAl, Bath AS Disease Activity Score; BASMI, Bath AS Metrology Index; CS, cervical spine; LS, lumbar spine; MRI, magnetic resonance imaging; mSASSS, modified Stokes AS Spinal Score; RCT, randomised controlled trial; TNF, tumour necrosis factor; TS, thoracic spine 
different groups of patients with AS: group 1 consisted of 41 patients with AS from the first RCT on infliximab recently published. $^{513}$ In this group, all patients were treated according to a standard protocol with $5 \mathrm{mg} / \mathrm{kg}$ infliximab intravenously continuously every 6 weeks. Group 2 consisted of another 41 patients with AS selected randomly from the German AS cohort (GESPIC), who were treated conventionally. The observation time for all patients was 2 years, with assessment at two different time points: baseline and 2 years' follow up. Table 1 shows the patients' characteristics at baseline.

\section{Radiographic assessment of the spine}

Lateral radiographs of the lumbar spine (LS) and the cervical spine (CS) were available from all patients who were included in this study. Radiographs were obtained in all patients at two time points, at baseline and at follow up after 2 years. After blinding for patients' treatment and time order, all images were scored by one experienced observer using the mSASSS. ${ }^{10}$ Comparison of the radiographic progression in each person and both groups was performed by evaluating the change of the mSASSS between the time points.

\section{Radiographic scoring by the mSASSS}

This scoring method is a modification of the original SASSS. ${ }^{15}{ }^{16}$ It evaluates the anterior part of the LS and the CS by assessing chronic changes using a score between 0 and 3 (fig 1). The LS is scored from the lower border of the 12th thoracic vertebral body to the upper border of the first sacral vertebral body. The CS is scored from the lower border of the second cervical vertebral body to the upper border of the first thoracic vertebral body. Thus, the score ranges from 0 to 72 points.

A well known problem of imaging and scoring procedures is that not all images are of perfect quality (over- or underexposure of the radiograph) and the spinal segments are not always completely captured on one film, which might lead to some sites being missed. In this study we excluded patients who had more than three vertebral sites missing. In the cases with $\leqslant 3$ vertebral sites missing, the missing scores were substituted by the mean score of the vertebra of the same spinal segment of the patient.

For the definition of mSASSS, definite radiographic damage at baseline was defined as an mSASSS score of $\geqslant 2$ (appearance of at least one syndesmophyte) in at least one vertebral edge of each individual patient. Definite radiographic change (including worsening or improvement) was defined as an mSASSS change of $\geqslant 2$ points in the mSASSSin accordance with the data provided by Creemers et al. ${ }^{17}$

Table 1 Patients' characteristics for the two compared groups at baseline

\begin{tabular}{|c|c|c|c|}
\hline Characteristics & $\begin{array}{l}\text { Infliximab } \\
\text { group } \\
(n=41)\end{array}$ & $\begin{array}{l}\text { GESPIC } \\
\text { cohort } \\
(n=41)\end{array}$ & p Value \\
\hline \multirow{7}{*}{$\begin{array}{l}\text { Mean age (range) } \\
\text { Mean disease duration } \\
\text { (range) } \\
\text { Male, No (\%) } \\
\text { HLA-B27 positive, No (\%) } \\
\text { Mean BASDAl, range } \\
\text { Patients with mSASSS >0, } \\
\text { No (\%) } \\
\text { Mean mSASSS at baseline }\end{array}$} & $38.9(21-53)$ & $34.8(22-76)$ & \multirow{2}{*}{$\begin{array}{r}0.005^{*} \\
<0.001^{*}\end{array}$} \\
\hline & $15.5(3-35)$ & $5.5(1-10)$ & \\
\hline & $26(63)$ & $29(71)$ & 0.3 \\
\hline & 37 (90) & 35 (85) & 0.5 \\
\hline & $6.3(3.8-8.8)$ & $3.2(0.2-7)$ & $<0.001^{*}$ \\
\hline & $23(56)$ & $16(39)$ & $0.05^{*}$ \\
\hline & 12.1 & 5.9 & $0.026^{*}$ \\
\hline
\end{tabular}

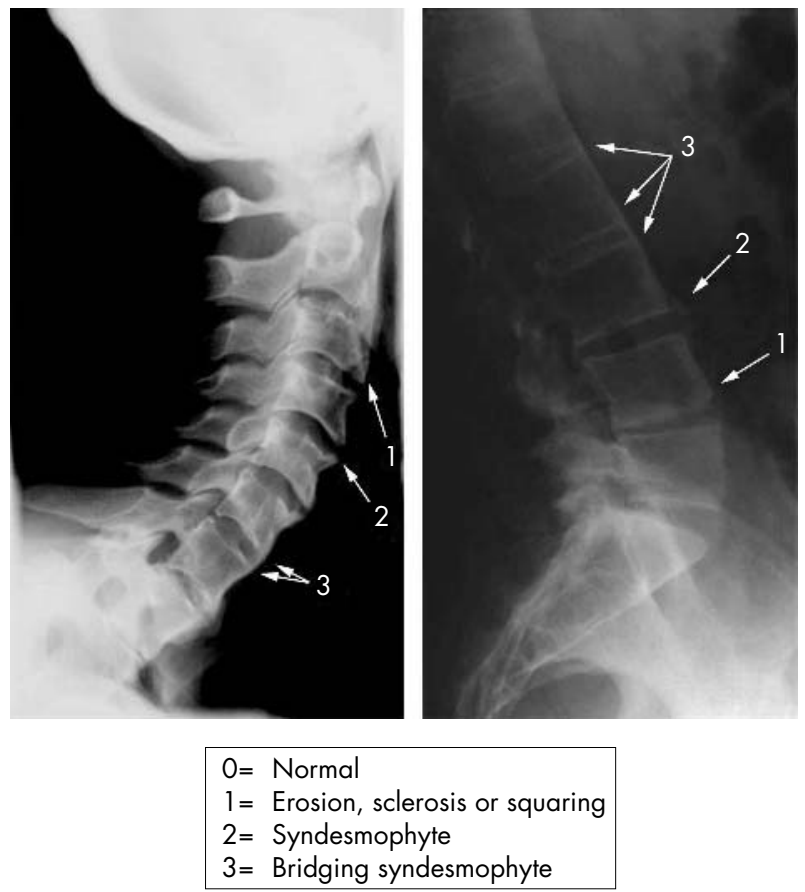

Figure 1 The mSASSS. Chronic spinal changes are assessed by scoring the anterior vertebral edge of each vertebra between the lower edge of C2 and the upper edge of Th1, and between the lower edge of Th 12 and the upper edge of $\mathrm{S1}$.

\section{Statistical analysis}

Correlation of the data at the two time points was calculated by Pearson's correlation coefficient. Non-parametric tests were applied to identify radiographic progression. For simple comparisons within each group Wilcoxon's test was used. For comparison of radiographic progression between groups 1 and 2 a test recently proposed by Brunner $e t$ al ${ }^{18}$ was applied. This test adjusts for the observed differences at baseline when actually comparing the differences in radiographic progression. An SAS macro, which was provided, ${ }^{19}$ was used for this calculation.

As scoring with mSASSS is very skewed but not normally distributed and the usual means are biased by extreme values, the pooled mSASSS scores of both time points and both groups were transformed into normalised rank scores (van der Waerden scores), which have a mean of 0 and an $\mathrm{SD}=1$, in order to further assess evaluation of radiographic progression. Changes in normalised rank scores were compared by analysis of covariance.

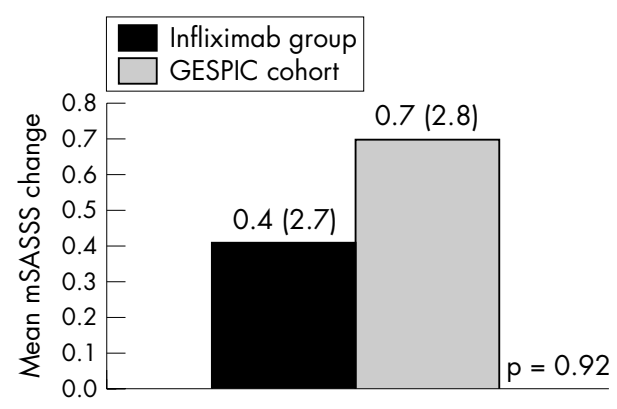

Figure 2 Comparison of the mean radiographic progression over the 2 year study period for all patients in the two assessed groups. 


\section{RESULTS}

\section{Patients' characteristics at baseline}

Patients in the GESPIC cohort group were younger than patients in the infliximab group, and the mean disease duration was significantly longer in the infliximab group $(p=0.005$ and $p<0.001$, respectively; table 1$)$. Furthermore, patients in the infliximab group had a higher overall level of radiographic damage at baseline $(p=0.026)$. Patients in the infliximab group also had a higher level of disease activity, as assessed by the Bath AS Disease Activity Index $\left(\right.$ BASDAI $\left.^{20}\right)$ at baseline. To be included in the RCT with infliximab, patients had to have a BASDAI score $>4$. Furthermore, there were significant differences between the two groups for the mean CRP level, the mean Bath AS Metrology Index (BASMI), and the mean Bath AS Functional Index (BASFI) (data not shown). There were no differences in the proportion of male patients and of HLA-B27-positive patients between the groups (table 1).

\section{Descriptive analysis of the radiographic scoring over 2 years}

The mean (SD) mSASSS for the patients in the infliximab group was 12.1 (16.9) and 12.5 (17.0) at baseline and follow up, respectively $(p=0.12)$, while the values for the patients in the GESPIC cohort were 5.9 (13.4) and 6.6 (14.8) for baseline and follow up, respectively $(p=0.07)$. Thus, the

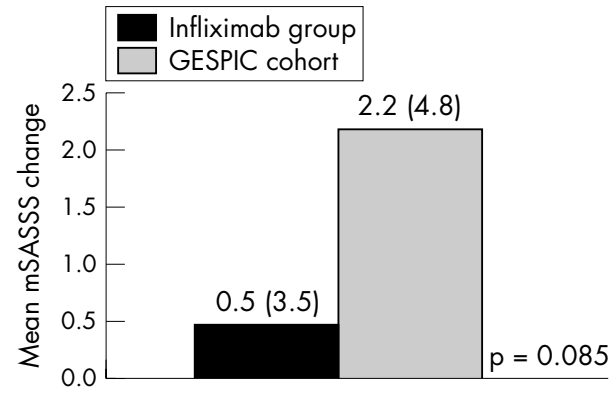

Figure 4 Comparison of the mean radiographic progression over the 2 year study period for patients with definite radiographic damage at baseline in the two assessed groups.

mean mSASSS change in the infliximab group was less than in the conventionally treated patients. Nevertheless, a comparison of the changes between the two groups did not show significant differences (figs 2 and 3 ).

When using normalised rank scores, a similar progression of chronic changes was found: patients in the infliximab group slightly worsened from a mean of 0.23 at baseline to a mean of 0.27 at follow up ( $\mathrm{p}=\mathrm{NS})$, while the patients in the GESPIC cohort worsened from a mean of -0.17 at baseline to a mean of -0.11 at follow up $(\mathrm{p}=\mathrm{NS})$.
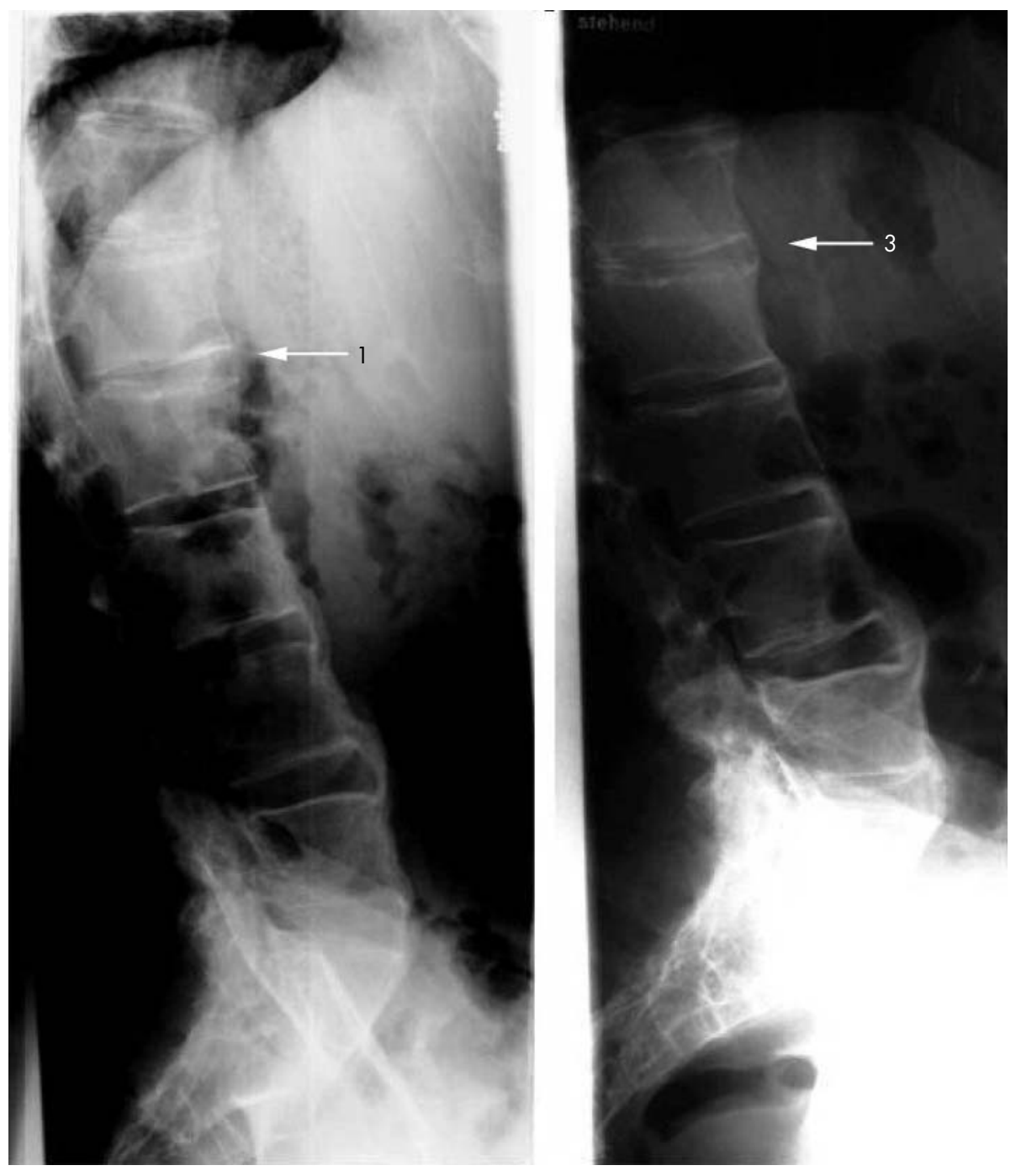

Figure 3 Example of a patient with radiographic progression. Erosion and sclerosis worsened to bridging syndesmophytes after 2 years. 
The proportion of patients with definite baseline damage (score $\geqslant 2$ in at least one vertebral edge) was higher in the infliximab group (24/41 (59\%) patients) than in the GESPIC cohort $(13 / 41(32 \%)$ patients) $(p=0.015)$.

The proportion of patients with definite radiographic progression was similar in both groups: $7 / 41$ (17\%) patients in the infliximab group and $5 / 41(12 \%)$ patients in the GESPIC cohort showed progression of $\geqslant 1$ scoring point after 2 years $(\mathrm{p}=\mathrm{NS})$.

\section{Radiographic progression in relation to the degree of baseline damage}

When the pooled data of all 82 patients were analysed to determine definite radiographic damage (at least one score $\geqslant 2$ in at least one vertebral edge) at baseline (37/82 (45\%) patients), patients with radiographic damage at baseline showed significantly higher rates of radiographic progression (mean (SD) mSASSS change 1.1 (3.9)) over the entire study period of 2 years than patients with no radiographic damage at baseline (mean (SD) mSASSS change 0.2 (0.8)), $(\mathrm{p}=0.028)$. Thus definite radiographic damage at baseline is a prognostic factor associated with continuing radiographic progression over time, possibly independent of treatment.

In the subgroup of patients with definite radiographic damage at baseline, no difference in the mSASSS was found between the two groups at baseline: mean (SD) mSASSS in the infliximab group $(n=24)$ was $20.1(18.0)$, and in the GESPIC cohort $(\mathrm{n}=13)$ was 17.1 (19.4) $(\mathrm{p}=\mathrm{NS})$.

However, in a subgroup analysis of those patients with definite damage at baseline, the mean radiographic progression over 2 years showed a clear tendency for less progression of the mSASSS in the infliximab group $(0.5(3.5))$, than in the GESPIC cohort $(2.2(4.8)),(\mathrm{p}=0.08$ by Brunner test; fig 4).

Finally, by calculating normalised rank scores a similar trend with a mean radiographic progression of 0.002 for patients in the infliximab group and 0.1 for patients in the GESPIC cohort $(p=0.08)$ was found.

\section{Correlation of mSASSS scores with clinical parameters} The mean mSASSS values correlated well with scores for spinal mobility for both groups. There was significant correlation between mSASSS and BASMI values in both groups at baseline $(r=0.49$ and $r=0.51$ for the infliximab group and the GESPIC cohort, respectively, both $\mathrm{p}=0.01$ ) and at follow up in the infliximab group $(r=0.59$ and $\mathrm{p}=0.01$ for the infliximab group, $r=0.48$ and $\mathrm{p}=0.01$ for the GESPIC cohort). No correlation between mSASSS and all other clinical parameters was found at both time points. Similarly, there was no significant correlation between changes of clinical parameters and the change of the mSASSS over the entire study period (data not shown).

\section{DISCUSSION}

This study suggests that treatment with the anti-TNF antibody infliximab may influence the progression of chronic radiographic changes in patients with AS because a tendency for deceleration of $x$ ray progression with continuous infliximab treatment over 2 years was found in the subgroup with most damage at baseline and over time.

Our investigator driven clinical study was accepted by the European Medicines Agency (EMEA) and used as the major data source to approve infliximab for the treatment of the signs and symptoms of patients with active AS in Europe. Thus we thought it important to analyse the 2 year data also in relation to structural damage. To achieve this we used the best $x$ ray scoring method available, the mSASSS, ${ }^{8}{ }^{17}$ which concentrates on lateral radiographs of the CS and the LS with only the anterior rim of the vertebral bodies being scored, the total range is $0-72$. The thoracic spine (TS) and zygapophyseal joints are not part of this $x$ ray based system because of the limited ability of two dimensional imaging at these sites.

As randomised controlled studies performed to compare the efficacy of anti-TNF agents in comparison with placebo in patients with AS over 2 years are not considered ethical, the only to way to gain information about structural damage is to compare actual data with historical control groups.

At the moment only two cohorts are available and only one has a sufficiently large dataset of radiographs, while the other dataset is currently undergoing further analysis: the international longitudinal observational study of outcome in AS $\left(\mathrm{OASIS}^{8}\right)$ and the German Spondyloarthritis Inception Cohort. ${ }^{21}$ The data of the latter were available to us, but we could only make the comparison with the OASIS dataset on the basis of a recent publication with 133 patients from this cohort, ${ }^{8}$ who showed similar characteristics at baseline as the patients included in our infliximab group. Although the groups studied have different demographics, we were confident that analysis could be carried out because we had data available for more than 200 patients with AS which could be used to compare the rates of radiographic progression.

In comparison with other cohorts, patients treated with infliximab showed less radiographic change over 2 years (mean mSASSS change 0.4) despite a higher mean age, a longer disease duration, and a higher level of radiographic damage at baseline (all predictive of more damage over time) than the patients from the younger AS group (GESPIC, mean mSASSS change 0.7), who were conventionally treated. In addition, the comparable patients of the OASIS cohort showed clearly more mean radiographic progression (mSASSS score 2.8 points) after 2 years than the infliximab group.

When the two groups were compared after adjustment for baseline damage, the main predictor for radiographic progression, we saw a clear tendency for more radiographic progression after 2 years in the patients of the GESPIC cohort than in the patients treated with infliximab.

The finding that the radiographic progression in the whole group was not significantly different at the two time points can be mainly explained by the insufficiently large sample size of the study, ${ }^{13}$ which was not initially designed to look at structural damage as a primary end point. Secondly, as already mentioned, there are limitations to the scoring system because not all affected structures are included in the analyses. Thus, changes in the TS are not assessed by the mSASSS because conventional radiographs of this part of the vertebral column are difficult to read and scores are unreliable owing to the superimposed lung tissue. However, as recently confirmed this part of the spine is most commonly affected in AS. ${ }^{22}$ Data from a recent imaging study have suggested that AS related chronic spinal changes can be reliably assessed using $\mathrm{T}_{1}$ weighted MRI sequences, also in the TS. ${ }^{9}$ It is likely that the dataset of the ASSERT ${ }^{23}$ MRI study will help to evaluate further the usefulness of MRI for assessing chronic changes in AS. The long term MRI data which have been partly obtained from this patient cohort treated with infliximab will be analysed in the near future.

Another important finding of this study is that patients with AS with prevalent radiographic damage at presentation are significantly more likely to have more radiographic progression over time. This confirms a recent report published in abstract form. ${ }^{24}$

As the efficacy of anti-TNF compounds on the progression of chronic spinal changes will be an important issue in current and also in future studies, this needs to be taken into account when patients are selected and data are evaluated. 
Most rheumatologists would assume that an increased disease activity is associated with chronic changes in patients with AS. However, this is as yet unproved. Because infliximab has shown significant improvement of disease activity, both clinically and by MRI, ${ }^{73}{ }^{25}$ it is possible that infliximab also affects the chronic spinal changes demonstrated by $x$ ray examination in long term follow up studies. Interestingly, we found no correlation between the change of BASDAI scores or any other clinical parameters and the change of the mSASSS over the entire study period for both groups. This might be because improvement of disease activity is not directly linked to new bone formation and chronic changes. Thus, more extensive long term follow up examinations with larger patient numbers are needed to study this in more detail. Nevertheless, the radiographic scores at both time points correlated significantly with values of spinal mobility as assessed by the BASMI, which suggests that there is a direct relationship between radiological and clinical findings.

This study suggests that chronic spinal lesions may progress more slowly in patients treated continuously with infliximab. More studies with larger patient numbers are needed to prove that radiographic progression can be inhibited by drug treatment. More evidence will possibly be obtained from current large trials with infliximab, etanercept, and adalimumab. However, the spinal radiographs from these trials will also be compared with historical cohorts because the study design did not include direct control groups.

\section{Authors' affiliations}

X Baraliakos, J Brandt, J Braun, Rheumazentrum Ruhrgebiet, Herne,

Ruhr University Bochum, Germany

J Listing, German Rheumatism Research Centre, Berlin, Germany

M Rudwaleit, J Sieper, Rheumatology, Charité Medical School, Campus Benjamin Franklin, Berlin, Germany

\section{REFERENCES}

1 Braun J, Bollow $M$, Remlinger G, Eggens U, Rudwaleit $M$, Distler A, et al. Prevalence of spondylarthropathies in HLA-B27 positive and negative blood donors. Arthritis Rheum 1998;41:58-67.

2 Braun J, Sieper J. The sacroiliac joint in the spondyloarthropathies. Curr Opin Rheumatol 1996:8:275-87.

3 Braun J, BM, Sieper J. Radiology and pathology of the spondyloarthropathies. Rheum Dis Clin North Am 1998:697-735.

4 van der Heijde D, Boonen A, van der Linden Sj, Boers M. Reading radiographs in sequence, in pairs or random in rheumatoid arthritis: influence on sensitivity to change [abstract]. Arthritis Rheum 1997;40(suppl):287.

5 Braun J, Brandt J, Listing J, Zink A, Alten R, Golder W, et al. Treatment of active ankylosing spondylitis with infliximab: a randomised controlled multicentre trial. Lancet 2002;359:1187-93.
6 Gorman JD, Sack KE, Davis JC Jr. Treatment of ankylosing spondylitis by inhibition of tumor necrosis factor alpha. N Engl J Med 2002;346:1349-56.

7 Braun J, Baraliakos X, Golder W, Brandt J, Rudwaleit M, Listing J, et al. Magnetic resonance imaging examinations of the spine in patients with ankylosing spondylitis, before and after successful therapy with infliximab: ankylosing spondylitis, before and after successful therapy with infliximab:
evaluation of a new scoring system. Arthritis Rheum 2003;48:1126-36.

8 Wanders AJ, Landewe RB, Spoorenberg A, Dougados M, van der Linden S, Mielants $\mathrm{H}$, et al. What is the most appropriate radiologic scoring method for ankylosing spondylitis? A comparison of the available methods based on the Outcome Measures in Rheumatology Clinical Trials filter. Arthritis Rheum 2004;50:2622-32.

9 Braun J, Baraliakos X, Golder W, Hermann KG, Listing J, Brandt J, et al. Analysing chronic spinal changes in ankylosing spondylitis: a systematic comparison of conventional $x$ rays with magnetic resonance imaging using established and new scoring systems. Ann Rheum Dis 2004;63:1046-55.

10 Creemers MC, Franssen MJ, van't Hof MA, Gribnau FW, van de Putte LB, van Riel PL. Assessment of outcome in ankylosing spondylitis: an extended radiographic scoring system. Ann Rheum Dis 2005;64:127-9.

11 Wanders A, van der Heijde D, Landewe R, Behier JM, Calin A, Olivieri I, et al. Inhibition of radiographic progression in ankylosing spondylitis (AS) by continuous use of NSAIDs [abstract]. Arthritis Rheum 2003;48(suppl):S233.

12 Braun J, Brandt J, Listing J, Zink A, Alten R, Burmester G, et al. Long-term efficacy and safety of infliximab in the treatment of ankylosing spondylitis: an open, observational, extension study of a three-month, randomized, placebocontrolled trial. Arthritis Rheum 2003;48:2224-33.

13 Braun J, Brandt J, Listing J, Zink A, Alten R, Burmester G, et al. Two year maintenance of efficacy and safety of infliximab in the treatment of ankylosing spondylitis. Ann Rheum Dis 2005;64:229-34.

14 van der Linden S, Valkenburg HA, Cats A. Evaluation of diagnostic criteria for ankylosing spondylitis. A proposal for modification of the New York criteria. Arthritis Rheum 1984;27:361-8.

15 Averns HL, Oxtoby J, Taylor HG, Jones PW, Dziedzic K, Dawes PT. Radiological outcome in ankylosing spondylitis: use of the Stoke Ankylosing Spondylitis Spine Score (SASSS). Br J Rheumatol 1996;35:373-6.

16 Taylor HG, Beswick EJ, Dawes PT. Sulphasalazine in ankylosing spondylitis. A radiological, clinical and laboratory assessment. Clin Rheumatol $1991 ; 10: 43-8$.

17 Creemers MC, Franssen MJ, van't Hof MA, Gribnau FW, van de Putte LB, van Riel PL. Assessment of outcome in ankylosing spondylitis: an extended radiographic scoring system. Ann Rheum Dis 2005;64:127-9.

18 Brunner E, Domhof S, Langer F. Nonparametric analysis of longitudinal data in factorial experiments. New York: Wiley, 2002.

19 Brunner E. Longitudinal dat macro. http://www.ams.med.uni-goettingen.de/ $\mathrm{de} /$ sof/ld/makros.html (accessed 18 July 2005).

20 Garrett S, Jenkinson T, Kennedy LG, Whitelock H, Gaisford P, Calin A. A new approach to defining disease status in ankylosing spondylitis: the Bath Ankylosing Spondylitis Disease Activity Index. J Rheumatol 1994;21:2286-91.

21 Braun J, Sieper J. [Inception cohorts for spondyloarthropathies]. Z Rheumatol 2000;59:1 17-21.

22 Baraliakos X, Landewe R, Hermann KG, Listing J, Golder W, Brandt J, et al. Inflammation in ankylosing spondylitis - a systematic description of the extent and frequency of acute spinal changes using magnetic resonance imaging. Ann Rheum Dis 2005;64:730-4.

23 Hermann KG, Landewe R, Braun J, van der Heijde D. Magnetic resonance imaging of inflammatory lesions in the spine in ankylosing spondylitis clinical trials: is paramagnetic contrast medium necessary? J Rheumatol, (in press).

24 van der Heijde D, Wanders A, Mielants $H$, Dougados $M$, Landewe R. Prediction of progression of radiographic damage over 4 years in patients with ankylosing spondylitis [abstract]. Ann Rheum Dis 2004;63(suppl 1):98.

25 Braun J, Baraliakos X, Brandt J, Listing J, Zink A, Alten R, et al. Persistent clinical response to the anti-TNF antibody infliximab in patients with ankylosing spondylitis over 3 years. Rheumatology (Oxford) 2005;44:670-6. 